\title{
Editorial
}

\section{A policy set in stone}

\author{
Journal of Building Appraisal (2007) 3, 89-96. doi:10.1057/palgrave.jba.2950070
}

Appraising buildings involves a process of investigation. The aim of that process is to understand how the building is performing and in what way any limitations in its performance may affect the future occupation or ownership of the premises. The understanding of the consequences of the condition is a key part of this activity. That is a process that will involve deciding if, how and in what way any limitation could or should be remedied.

Remedying a defect is not a process for which there is a single answer. Many years ago there was a West Country shop occupied by a major high street retailer that had a leaking flat roof. The options for the remedying of that defective roof did not lie within the anticipated range between a patch and the replacement of the roof covering; they also included the addition of a new storey on top of the defective roof level.

In nearly every case where there is a defect the options available for the remedy of that defect may be constrained by costs, by liability, by disruption, the time when the problem is to be eliminated, statutory processes and consents. How much the alternative methods of repair may cost may be one of the major drivers in the decision-making process, but the durability of the remedy should make no less a contribution to the selection process.

Cheap is rarely the best. The contractor who supplies the lowest quotation often fails to complete to achieve a satisfactory standard of work, increases the time involvement of those responsible for management of the works, or abandons the project before a satisfactory conclusion. In the past weeks I have watched project after project being abandoned in Eastern Europe because of the economic migration of construction workers, leaving the home market denuded of skilled workers, and as a result, leading to projects collapsing. When construction costs are 40 per cent of those in the UK it is difficult to persuade the workforce not to migrate to an alternative and better-paid life. It is not just the workers who are migrating, some established construction firms are relocating as well.

Even where you have control over the building and the decision-making process, the decision on how to remedy a defect should depend upon selecting the best solution at the given time. Few people are, however, gifted such freedom. It is more usual for the decisions to be influenced by the contract between a landlord and a tenant, by building regulations that identify the technical standards the repair is to achieve, by tried and understood methods (irrespective of their success) or by planning controls that may expect defined materials to be used.

Landlord and Tenant contracts impose responsibilities on the repairing party in terms of the performance of the repair, the timescales before the repair is carried out, notices that may have to be served, licences that have first to be obtained and in some cases the consents expected before works can begin. These demands often conflict, and it is in the resolution of conflict that Building Appraisers come into their own.

The planning designation of the building often affects the decision as to the method of repair to be adopted. The replacement of defective roofing for warehouses now converted into loft living resulted in a condition being imposed that the roof finish should be profile metal sheeting. This, according to the planners, was to reflect the industrial heritage of the 
building. Crinkly tin, as such roofs are often referred, is a poor material for a residential property, being noisy when it rains. It is also, being a metal, a conductor - in this case of sound. The transmission of sound from one unit to another was of embarrassment to those occupying homes next to regular night-time performers. So poor was the sound resistance that in the morning the neighbours placed cards in the front window marking their neighbours' nocturnal coupling for technical merit and style. On another project where the former industrial space was converted to office use continuous problems were experienced with water leaks where lead flashings had been applied over the profile sheeting with limited success. (Have you tried hammering a lead flashing into the shape of a metal profile sheet on an insubstantial base - you end up flattening the crinkly tin rather than moulding the metal flashing).

Most people expect their repaired premises to portray no sign of the past problem. If your car was in an accident you expect the repaired car to show no traces of the former coming together, if your home was in a fire you expect the repaired building to carry no traces of the conflagration. But if your building is listed as being of architectural and historic interest remedying disrepair becomes a challenging philosophical discussion. Repair is not just selecting a remedy that eliminates the consequences of the decline in performance, it is a judgment as to the type of appearance that the remedy should have. Here, in the analogy of the car, the evidence of that bump may have to be very evident after the process of repair so that the original car is able to be differentiated from that part that has been repaired.

For a listed building the remedial options may be as follows:

- the use of contrasting materials that obviously define the replaced parts;

- the use of matching materials where the replaced components are finished in such a way that the replacement can be identified from the neighbouring original materials;

- the use of new materials to replicate the appearance;

- the use of matching materials provided with a finish that replicates the original appearance of the surfaces when first built so that the weathered adjoining materials are in clear contrast to the replaced material;

- the use of matching materials that have been finished with a weathered finish that matches the adjoining parts of the building so that the replacement is indistinguishable from the remainder of the unchanged parts of the property.

The property owner will want the latter repair because that leaves his or her property free from the unsightly blemishes caused by nonmatching repairs. The problem for those directing repairs and interpreting the decisions of various Heritage Bodies has been the inconsistency of approach and the lack of a discernable policy directing the outcomes on a building-by-building basis. The impenetrable decision process, and the time taken for a decision to be made frequently left those who have to plan the remedial works with considerable doubt as to how a specific property was to be treated, and how.

The UK Government has published a policy consultation paper setting out the guidance for this decision-making process. The second stage of the consultation over 'Conservation Principles for the sustainable management of the Historic Environment' was published by English Heritage and the subsequent consultation period ended on 11th May, 2007.

The aim of the authors of this Policy Document is to provide a logical approach to making decisions and offering guidance on a consistent basis about any and all aspects of the historic environment, and for balancing its protection with the economic and social 
needs and aspirations of the communities who live in it. These Conservation Principles, Policies and Guidance should offer both a response to the limitations of the existing separate designation and management regimes, and a contribution to their proposed rationalisation, following the modernisation of spatial planning through Local Development Frameworks. The Principles are primarily intended to help English Heritage achieve greater consistency of approach in carrying out its statutory role as the Government's advisor on the historic environment in England.

Sustainable management of a place begins with understanding and articulating how, why, and to what extent it has heritage, in other words its heritage value. Only through understanding the significance of a place is it possible to assess how the qualities that people appreciate are vulnerable to harm or loss. That understanding should then provide the basis for developing and implementing management strategies (including maintenance, cyclical renewal and repair) that will best sustain the heritage values of the place in its setting.

Conservation is defined within this paper and includes the prime objective of sustaining the heritage values of a place.

- 'Preserve', even its established legal definition of 'to do no harm', is only one aspect of what is needed to sustain these values. The conservation area concept, with its requirement 'to preserve or enhance', also recognises that potential often exists for beneficial change which can reveal and reinforce value.

- 'Sustain' embraces both preserve and enhance to the extent that the values of a place allow.

- 'Change' offers the potential to enhance and add value to places, as well as generating the need to protect their established heritage values. It is the means by which each generation aspires to enrich its historic environment, to make changes that will, in turn, be valued by the generations to come.

Extracts from the principle policies have been set down below but it is the philosophy behind the policy that is of greater interest.

Heritage values express the public interest in our historic environment (Principle 1, page 15), regardless of ownership. Use of law and public policy to the extent necessary to protect that public interest is justifiable if it is supported by advice and assistance to help owners to sustain the heritage. In order to identify the heritage values of a place (Principle 3 , page 17), it is necessary first to understand its fabric, and how and why it has changed over time; and then to consider:

- who values the place, and why they do so;

- how those values relate to its fabric;

- their relative importance;

- whether they are enhanced by associated objects;

- the contribution of the setting and context of the place to its values;

- how well the place compares with others sharing similar values.

Conservation is the process (Principle 4, page 18) of managing change in ways that will best sustain the significance of a place in its setting, while recognising opportunities to reveal or reinforce its values for present and future generations. Conservation is achieved 
by everyone concerned with managing a significant place sharing an understanding of its significance, and using it to

- judge how its heritage values are vulnerable to change;

- take the actions and impose the constraints necessary to sustain, reveal and reinforce those values;

- mediate between conservation options, if action to sustain one heritage value could conflict with action to sustain another;

- ensure that the place retains its authenticity.

If conflict cannot be avoided (Principle 5, page 19), the weight given to heritage values in making the decision should be proportionate to the significance of the place and the impact of the proposed change on it.

People may value a place for many reasons: its distinctive architecture or landscape, the story it can tell about its past, its association with notable people or events, its landform, flora and fauna, because they find it beautiful, awesome or inspiring, or for its role as a focus of an established community.

To assist in the decision-making process as to the importance of a place, key concepts are listed. The Values expressed are Evidential, Historical, Aesthetic and Communal. In order to assess the significance of a building or place, its fabric and character must first be understood. This should include its origins, how and why it has changed over time (and will continue to change if undisturbed), the form and state of its constituent elements and materials, any habitats it provides, and how and why it differs from other places.

The full range of heritage values that people attach to a place should be understood. Among the complexities of dealing with older premises are the changing preferences of people. For example, for years 1960s architecture was derided and building after building demolished. Now it has achieved a status that results in their being efforts made to conserve (or preserve) examples of this period. This changing face of heritage values can come as a surprise to those dealing with the alteration or renovation of property that has been unloved for generations only to find that it has been discovered just before the programme of works is to start.

Once the heritage value of a place has been identified it is important to consider the relative importance of the various values ascribed. The conflicting views will mean that a judgment must be reached as an essential part of the decision-making process. To achieve this balance one should consider:

- that historically associated objects can make a major contribution to the values of a place, and association with a place can add cultural value to those objects;

- the setting or surroundings of the place;

- an assessment of the importance of the place when compared with other places. Value judgments about our historic environment have implications for both places and everyone with an interest in them. Such judgments provide the basis for decisions about whether, or to what extent, a place should be conserved, rather than remade or replaced; - 'statement of significance' of a place is an overview of all the heritage values attached to it by all who have an interest in it. It should explain the relative importance of those values.

The Universal Considerations identified for the application of a Policy include considering the authenticity and integrity of the place, the sustainability and reversibility 
of a process being considered and the expectation of appropriate routine management and maintenance of the place.

The key decisions that have to be made relate to 'Periodic Renewal'. This should be acceptable where it was intended or inherent in the original design unless the process may cause harm to heritage values. For example, replacing gutters and downpipes is an accepted part of managing the maintenance of a building.

Repair is the battle ground. I had this in mind when I visited Castel del Monte with the engineer, Professor De Tomasi, who had designed and supervised the repairs of the building in the last century. This building in Puglia (bottom right corner of Italy) combines various original features which include an ancient-style gateway in the shape of a triumphal arch framing a pointed arch, ribs which stand out clearly on the ribbed vaults descending on to telamon-shaped sculpted bases and highly perfected hydraulic installations, mosaic and incrusted marble decoration. The interior had been degraded by the removal or decay of its marble and mosaic decoration, but there have been few later interventions. Conservation work since 1878 has been of a high order, consistent with Italian standards, and so the authenticity of the monument is high. It is now a World Heritage Site.

Castel de Monte has been the subject of various programmes of repair since it came into State ownership in 1878. Consolidation and stabilisation work took place between 1879 and 1902. In 1928/32 a number of later dry stonewalls were removed and the soil level round the perimeter was changed. Final consolidation work took place in 1962-1965 and the last batch of work undertaken under by Professor De Tomasi was carried out between 1975 and 1981. This work dealt with the repair of the stonewalls which had been extensively damaged and weathered over the life of the building (Figure 1). Some of the damage was caused by previous repairs (Figure 2). The initial repairs had sought to use matching stone from the original quarries, but this was laid against its natural bed to distinguish original work from the repair and as a result failed early in its life. The stone is a brittle limestone that breaks up in cold winds. This has resulted in much damage to the external face of the stonewalls and internal damage opposite the arrow slit windows on the outside of the building.

Because the building's earlier repairs had failed, De Tomasi decided to reuse stone from the original construction by adapting the parapets of the building to high level and then adopted the use of epoxy resins to repair the stone faces with the use of debris recovered from within and around the building. The fractured faces of the stonework were drilled and stainless steel pegs used to secure new stone shards, and to form a base for the application of the resin mixed with stone debris and dust. The replaced stonework is clear to see while achieving a finish that is reminiscent of the original and undamaged stone surfaces (Figure 3).

To replace the stone with a matching stone is to create a new castle, to use stone against its natural bed reinstates with a clear distinction as to where the stone has been replaced, but the stone has failed within 30-40 years. The epoxy resin repair reuses the greatest amount of the original materials, leaves a building reminiscent of the original appearance, yet shows the repairs as a contrast to the original materials.

The English Heritage Policy proposals suggest that repair and adaptation intended to sustain the heritage values of a significant place should be acceptable if all the following criteria are met:

- there is sufficient information about the place fully to understand the impacts of the proposals on its significance; 


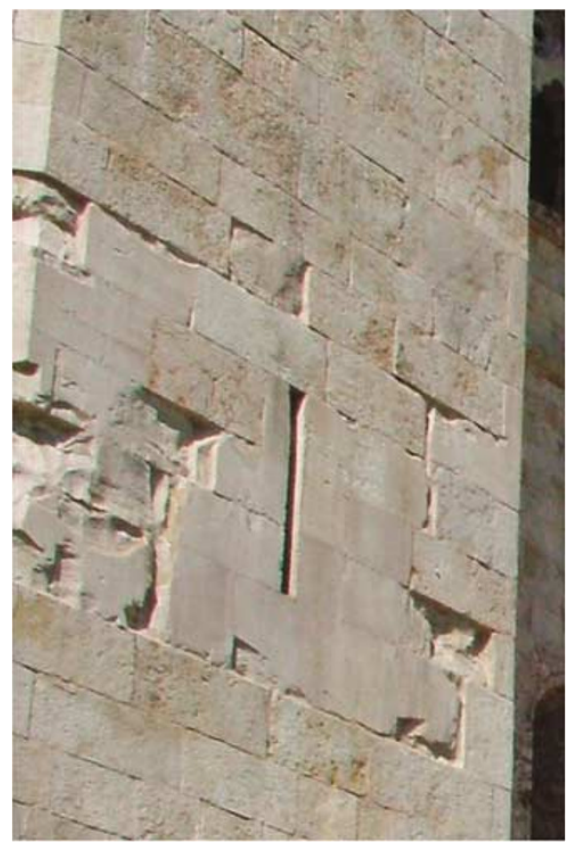

Figure I: Damaged stone face to high level



Figure 2: Damage resulting from World Heritage Status causing greater visitor numbers and etching of the stone around the entrance. Epoxy repairs are visible 45 years after they were carried out and the infil to the stainless steel pins can be located where the face of stones was refixed to the former stone 


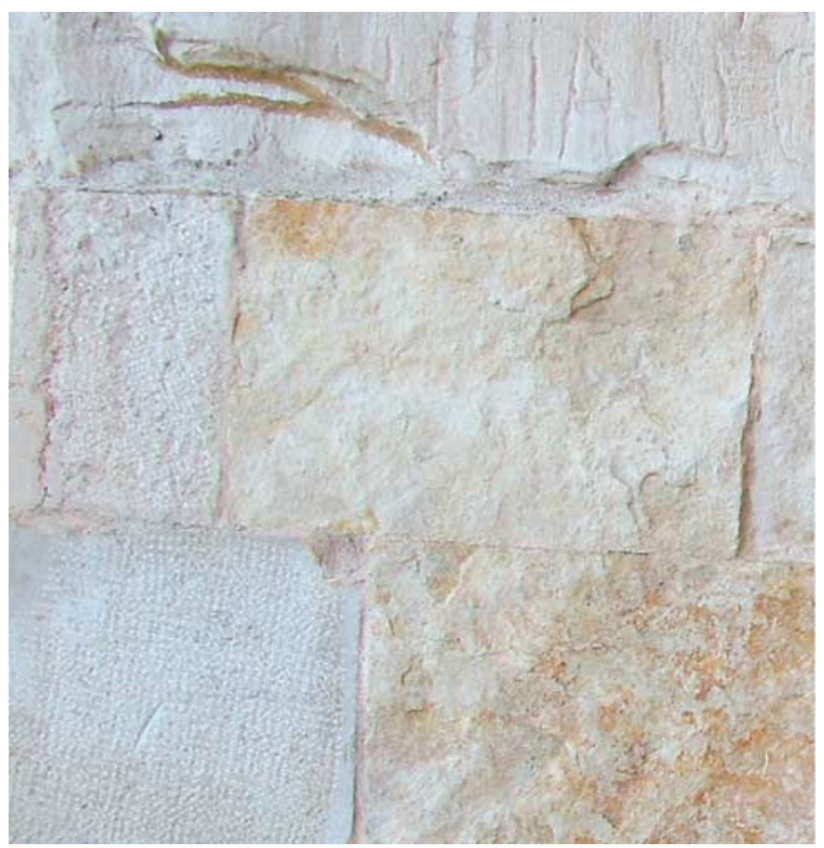

Figure 3: Replaced stonework in near matching stones finished with a different face to make then easy to recognise (bottom left). Epoxy resin repairs to the face of a stone using salvaged pieces of material and stone dust (top stone)

- the heritage values that would be affected have been identified, and their relative importance to the place understood;

- the long-term effects of the proposals can, from experience, be predicted to be benign, or are designed not unduly to prejudice other options in the future;

- harm arising from conflicting requirements to sustain different heritage values has been avoided, or minimised through considering both the relative importance of the values affected and the impact on them.

Restoration is an intervention, and its affect on a significant place should be acceptable if all the following criteria are met:

- the heritage value of what would be revealed or recovered decisively outweighs the value of what would be lost;

- the work proposed is justified by compelling evidence of the previous form of the place, and is executed in accordance with that evidence;

- the current state of the place, the form in which it survives, is not the result of a historically significant event;

- there would be no obvious incongruity, through creating something that has never previously existed as an entity;

- resources are available to maintain what is restored.

Proposed changes that would materially harm the heritage values of a significant place should be unacceptable unless all the following criteria are met:

- the changes are demonstrably necessary either to make the place economically sustainable, or to meet another public policy objective; 
- it is either not reasonably practicable to avoid the harm by achieving the conflicting objective in a different way, or the harm has been reduced to the minimum consistent with achieving that objective;

- it has been demonstrated to the competent authority that the public benefit decisively outweighs the unavoidable harm to the values of the place, considering

- its comparative significance;

- the impact on that significance; and

- the benefits to the place itself and/or the wider community or society as a whole.

The development of a public policy in this troubled area must improve decision making, and more importantly give guidance to those who have been struggling to find a logic behind those decisions that have been made.

Malcolm Hollis

Managing Editor 